\title{
APLICAÇÃO DO MODELO DE NEUMAN E DIAGNÓSTICOS DE NANDA AO CUIDADO DO USUÁRIO DE CRACK
}

\author{
NEUMAN'S MODEL APPLICATION AND NANDA \\ DIAGNOSIS ON CRACK USER CARE
}

\section{APLICACIÓN DEL MODELO DE NEUMAN Y DIAGNÓSTICOS NANDA EN LA ATENCIÓN AL USUARIO DE CRACK}

\author{
Kallen DetTMann WandeKoKen* \\ Marluce Miguel de Siqueira ${ }^{* *}$
}

\begin{abstract}
RESUMO
Objetivo: A partir da complexidade do uso de crack e da sua gênese multifatorial, este artigo propõe a identificação dos diagnósticos de Enfermagem da North American Nursing Diagnosis Association (NANDA) diante do usuário de crack, fundamentada no Modelo de Betty Neuman. Fato é que a questão envolve aspectos biopsicosocioculturais, de desenvolvimento e espirituais que são desafios na atuação da Enfermagem. Método: Estudo de caso, descritivo, exploratório, com abordagem qualitativa, fundamentado em Neuman. Resultados: Foram identificados 14 diagnósticos de Enfermagem a partir dos estressores intra, inter e extrapessoais. Constatouse que o uso de crack surge diante de vários estressores anteriormente vivenciados e contribui para ativar as linhas de resistência do usuário. Conclusões: O Modelo de Neuman facilitou a identificação dos diagnósticos de Enfermagem da NANDA contribuindo para um 'novo olhar' do enfermeiro diante do usuário de crack ao considerar não só o uso da droga, mas sim os estressores e todas as variáveis do sistema.
\end{abstract}

Palavras chave: Cuidados de enfermagem, diagnóstico de enfermagem, crack cocaine.

\begin{abstract}
Objectives: From the complexity of crack use and its multifactorial genesis, this paper proposes the identification of nursing diagnoses of North American Nursing Diagnosis Association's (NANDA) on crack user, based on Betty Neuman model. The fact is that the issue involves psychological, social, cultural, spiritual and developmental aspects, wich are challenges in Nursing action. Method: A case study, descriptive, exploratory, with qualitative approach, based on Neuman. Results: 14 nursing diagnosis from intra, inter and extra personal stressors were identified. It was found that the crack use appears in reason of several previously experienced stressors and helps to activate the user lines of resistance. Conclusions: The Neuman model have facilitated the identification of NANDA nursing diagnosis, contributing to a new perspective about the nursing acre in front of the crack user, which now considers not only the drug, but also the stressors and all the system variables.
\end{abstract}

Key words: Nursing care, nursing diagnosis, cocaína crack.

\section{RESUMEN}

Objetivos: A partir de la complejidad del uso del crack y su génesis multifactorial, este estudio propone la iden-

\footnotetext{
* Enfermeira. Mestre em Saúde Coletiva. Pesquisadora do Centro de Pesquisas e Estudios sobre Álcool e Drogas (CEPAD). Universidade Federal do Espíritu Santo, Vitória - ES, Brasil. Email: kallendw@gmail.com

** Enfermeira. Prof Associada III do Departamento de Enfermagem e do Programa de Pós-graduação em Saúde Coletiva. Coordenadora de Pesquisa do CEPAD-CCS-UFES, Vitória - ES, Brasil. Email: marluce.siqueira@ufes.br
} 
tificación de los diagnósticos de enfermería de la North American Nursing Diagnosis Association (NANDA) en el usuario de crack, basado en el modelo de Betty Neuman. El hecho es que el problema implica aspectos biopsicosocioculturales, de desarrollo y espirituales que son un desafío para la acción de enfermería. Material y Método: Estudio de caso, descriptivo, exploratorio, con enfoque cualitativo, basado en Neuman. Resultados: Se identificaron 14 diagnósticos de enfermería a partir de los estresores intra, inter y extrapersonales. Se encontró que el consumo de crack surge ante varios estresores vividos en el pasado y contribuye a activar las líneas de resistencia de los usuarios. Conclusiones: El modelo de Neuman facilitó la identificación de los diagnósticos de enfermería de la NANDA, contribuyendo para un nuevo mirar de la enfermera frente al usuario de crack, al considerar no solamente el uso de la droga, sino también los estresores y todas las variables del sistema.

Palabras clave: Atención de enfermería, diagnóstico de enfermería, cocaína crack.

Fecha recepción: 09/08/12 Fecha aceptación: 20/06/13

\section{INTRODUÇÃO}

Desde o surgimento do crack, pesquisas apontam um aumento acelerado do consumo (1-3). No Brasil, por exemplo, o II Levantamento Domiciliar Nacional sobre o Uso de Drogas Psicotrópicas no Brasil, realizado pelo Centro Brasileiro de Informações sobre Drogas Psicotrópicas (CEBRID), nas 108 maiores cidades brasileiras aponta que 2,9\% dos entrevistados afirmaram ter usado cocaína ao menos uma vez na vida e $0,7 \%$ usaram crack. Na região Sudeste, esse índice chegou a 3,9\% em relação à cocaína e 0,9\% ao crack (1).

Além disso, segundo dados da Organização das Nações Unidas (ONU), têm ocorrido um declínio na demanda por cocaína nos mercados tradicionais, como Estados Unidos, o que favorece o aumento do consumo em países emergentes como o Brasil (2). Assim, é importante considerar que em pesquisa realizada pela Confederação Nacional dos Municípios Brasileiros, foram entrevistados os secretários de saúde e observou-se que em $98 \%$ dos municípios pesquisados haviam problemas decorrentes do crack, inclusive nos municípios pequenos, com menos de vinte mil habitantes (3).

O crack é considerado a forma com maior potencial de dependência da cocaína, além de ser o método preferível por muitos usuários por proporcionar efeitos eufóricos se- gundos após a sua inalação. Sendo a droga absorvida diretamente nos pulmões, o seu uso possibilita uma rápida ação da droga no cérebro, obtendo efeitos mais estimulantes e muitíssimos prazerosos para o usuário, o que caracteriza a 'fissura' quase incontrolável, descrita por muitos usuários (4). Assim, a grande dificuldade no tratamento seria "o estabelecimento de vínculo terapêutico com a instituição, e o manejo correto, por parte dos profissionais, da fissura" (5).

Nesse contexto, em pesquisa realizada com 30 usuários de crack, foram destacados como riscos de complicações físicas o emagrecimento, a insônia e a overdose (6). E em estudo de corte, realizado por 5 anos, com 131 usuários de crack, observou que as maiores causas de morte eram homicídios e Síndrome de Imunodeficiência Adquirida (AIDS) (7). Observa-se então que a relação entre o uso de crack e mortalidade não é direta, mas é fato que o índice de mortalidade entre os usuários é grande (4). Assim, segundo os pesquisadores, os óbitos estão mais relacionados comumente a elementos do tráfico, à disputa entre pontos de venda ou enfrentamentos com a polícia do que aos problemas decorrentes do uso da droga em si.

É interessante destacar, ainda, que a posição que o crack ocupa, hoje, na sociedade, é diferente das demais drogas, pois é, muitas vezes, compreendido como o maior responsável "por todos os problemas da sociedade", 
o que também é reforçado pela mídia (8). E ainda, que as políticas existentes que abordam a temática no cenário brasileiro possuem correntes ideológicas diferentes, pois a Política Nacional -do Conselho Nacional de Políticas sobre Drogas- está ligada, direta ou indiretamente, à segurança pública, e já a Política do Ministério da Saúde para Atenção Integral aos Usuários de Álcool e outras Drogas ressalta a necessidade da diversidade e pluralidade de ações neste campo (8). Assim, essas divergências e falta de interação entre as políticas de fato geram problemas em suas execuções (9).

Dessa forma, frente à complexidade da questão do uso do crack e devido à expansão do número de usuários, se fazem necessários profissionais de saúde capacitados na temática, em especial o enfermeiro, que deve, a partir do conjunto de necessidades do indivíduo, apreender os problemas dos usuários e propor estratégias assistenciais.

Nesse sentido, a Sistematização da Assistência de Enfermagem (SAE) auxilia na relação interpessoal entre enfermeiro e usuário, de forma que a comunicação é essencial nesta relação, pois favorece ao indivíduo reconhecer sua importância no autocuidado, tornando-se atuante na busca pela saúde. Para tanto, o planejamento da assistência de Enfermagem e o uso de teorias de Enfermagem que visam definir a Enfermagem enquanto ciência são fundamentais para compreender questões inerentes ao paciente, ao ambiente e para o desenvolvimento de um cuidado qualificado.

Assim, ressalta-se o Modelo de Sistemas proposto por Betty Neuman, que está sendo utilizado em diversos cenários de prática. $\mathrm{O}$ modelo é usado para orientar a prática com pessoas que apresentam comprometimento cognitivo; à família de pacientes em terapia intensiva; Enfermagem psiquiátrica; geriátrica, perinatal; saúde ocupacional; entre outros, embora no Brasil sua aplicação ainda seja um tanto escassa e não haja publicação da mesma no contexto do uso de crack (10).
O modelo foi publicado em 1972 como 'A Model for Teaching Total Person Approach to Patient Problems', em Nursing Research. Neuman descreve seu modelo como abrangente e dinâmico, de forma que o modelo enfatiza a reação da pessoa ao estresse e os fatores de reconstituição ou adaptação. Assim, para Neuman esse modelo pode ser utilizado pela Enfermagem de modo único na assistência (11).

A estrutura proposta é, basicamente, que cada indivíduo é visto como um sistema aberto constituído por um centro ('Core'), cercado por uma série de círculos concêntricos, onde estão incluídos os fatores básicos de sobrevivência comuns a todos os seres humanos e que se encontra rodeado por contornos hipotéticos: linha normal de defesa, linha flexível de defesa e linhas de resistência representada por diagrama que compreende os estressores ${ }^{l}$, a reação aos estressores e a reação à unidade total, interagindo com o ambiente (12).

Dessa forma, esse indivíduo -sistema aberto- está continuamente interagindo com forças internas e externas, ou estressores ambientais, e está em constante mudança no ambiente, movendo-se, todo tempo, em direção a um estado dinâmico de harmonia, equilíbrio ou bem-estar ou em direção a uma doença (12).

E considera ainda que fazem parte do sistema os estressores, a reação, a prevenção primária, secundária e terciária, os fatores intra, inter e extrapessoais (11). Assim, as linhas de resistência variam em tamanho e distância do reator e se trata dos fatores internos do indíviduo que são a defesa contra os estressores e tornam-se ativas quando a linha normal de defesa é invadida pelos estressores ambientais. Logo depois, segue a linha normal de defesa que é basicamente aquilo em que a

1 Estressores são forças ou estímulos que atuam sobre o cliente (sistema), que produzem tensão e que podem estar presentes no ambiente interno e externo do sistema, impedindo a manutenção do seu equilíbrio (12). 
pessoa se torna durante um período de vida, ou seja, o estado normal de bem-estar. Este é composto por habilidades fisiológicas, psicológicas, socioculturais, de desenvolvimento e espirituais, que são utilizadas pelo sistema para lidar com os estressores $(10,12,13)$.

Já a linha flexível de defesa é dinâmica e pode ser modificada rapidamente. Ela age como um amortecedor para a linha normal de defesa quando o ambiente é estressante, e ainda age como um 'filtro' quando o ambiente oferece apoio, servindo nesse contexto como uma força positiva que contribui para o crescimento e desenvolvimento (13). E à medida em que aumenta a distância entre esta e a linha de defesa, cresce o grau de proteção ao sistema.

Para entender os fatores estressores, algumas variáveis devem ser consideradas ao se pensar no individuo de forma holística, são elas: biológicas, psicológicas, socioculturais, de desenvolvimento e espirituais (13).

Assim, a variável biológica se refere à estrutura e às funções do organismo; a variável psicológica refere-se aos processos mentais e relacionamentos; a sócio-cultural tem haver com as expectativas e às atividades sociais $\mathrm{e}$ culturais; a de desenvolvimento se refere aos processos relativos ao crescimento durante o ciclo da vida; e já a variável espiritual diz respeito a influencia de crenças espirituais. Em uma situação ideal estas funcionam em harmonia e com estabilidade em relação aos estressores (12).

Dessa forma, é necessário explicitar que os estressores podem ser: 1) estressores intrapessoais -forças que ocorrem dentro do indivíduo (p. ex: raiva); 2) estressores interpessoais -referem-se às forças que ocorrem entre um ou mais indivíduos (p. ex: relação entre familiares); 3 ) estressores extrapessoais -forças que ocorrem fora do sistema e agem sobre o indivíduo (p. ex: desemprego) (12).

Assim, baseada nessas proposições, uma boa avaliação do impacto e do significado de cada estressor no sistema, e a compreensão das habilidades de enfrentamento, são fundamentais para uma adequada atuação de Enfermagem (10).

Diante desse contexto, será adotado como caminho estrutural o Modelo de Betty Neuman ao propor uma estratégia de atuação em Enfermagem para atenção a um usuário de crack comprometida com a manutenção da abstinência, na melhoria da qualidade de vida e na visão holística e multidimensional que lhe é inerente. E ainda, investigando os estressores individuais e ambientais, os recursos disponíveis, e os resultados (metas) estabelecidos na interação enfermeiro-usuário. Interação esta de fundamental importância nas proposições de ações educativas e/ou assistenciais no campo da dependência química.

Assim, diante das questões mencionadas, a pesquisa em questão tem o propósito de contribuir para a construção de um saber de Enfermagem Psiquiátrica / Saúde Mental, com especificidade no usuário de crack, de forma a conhecer a realidade deste caso e discutir diagnósticos de Enfermagem para embasar intervenções. Para tanto, este artigo propõe a identificação dos diagnósticos de Enfermagem da North American Nursing Diagnosis Association (NANDA) diante do usuário de crack, fundamentada no Modelo de Betty Neuman.

\section{MATERIAL E MÉTODO}

Trata-se de um estudo de caso, descritivo e exploratório, com abordagem qualitativa, fundamentado no Modelo de Betty Neuman.

Neste sentido, é importante destacar que há um consenso de que a temática sobre os usuários de crack exige uma abordagem difícil e complexa, pois é uma doença crônica e grave, bem como é de gênese multifatorial de forma que devem ser consideradas questões como fatores sociais, familiar, físico, mental, 
questões legais, qualidade de vida, prevenção de recaída, entre outros (4). Assim, o estudo de caso se torna apropriado para o aprofundamento das questões relacionadas a essa temática.

É importante destacar ainda que por se tratar de fenômeno social complexo a pesquisa apresenta abordagem qualitativa, pois o núcleo básico da pesquisa baseada nessa abordagem objetiva compreender o significado dado pelo sujeito aos fatos, relações, práticas e fenômenos sociais, e tem como objeto as relações humanas, as representações e a intencionalidade -questões que dificilmente podem ser traduzidas em indicadores quantitativos.

A pesquisa foi desenvolvida no Centro de Atenção Psicossocial - Álcool e Drogas (CAPSad) do município de Vitória, no Estado do Espírito Santo, Brasil. Os critérios de inclusão foram: 1) ter idade maior do que 18 anos; 2 ) relatar fazer o uso do crack como droga preferencial; 3) se dispuser a participar da pesquisa de forma voluntária; 4) estar iniciando o tratamento no CAPSad. E ainda, o 'caso' selecionado (denominado E.L.R.) para este estudo foi escolhido de forma aleatória entre os 50 sujeitos -da etapa transversal- do estudo multicêntrico do qual esta pesquisa está vinculada (14).

Foram observados os dispositivos legais da Resolução 196/96 do Conselho Nacional de Saúde - CNS (15), sendo que o estudo multicêntrico foi aprovado pelo Comitê de Ética em Pesquisa do Hospital de Clínicas de Porto Alegre - CEP-HCPA ( $n^{\circ}$ 100176) e a pesquisa em questão foi contemplada com aprovação do Comitê de Ética em Pesquisa do Centro de Ciências de Saúde da Universidade Federal do Espírito Santo - CEP-CCS-UFES (no 302/10). Os dados foram coletados somente após concordância e assinatura do Termo de Consentimento Livre e Esclarecido.

A coleta foi realizada em um único momento, após o acolhimento do sujeito no
CAPSad, em junho de 2011 e foram utilizados quatro instrumentos: 1) Questionário do padrão de consumo de crack - com 27 perguntas sobre o consumo da droga; 2) Escala de Gravidade de Dependência (ASI6) - avalia sete áreas de funcionamento, como moradia, emprego e família; 3) Mini Internacional Neuropsychiatric Interview (MINI Plus) - avalia 17 comorbidades psiquiátricas, e o Parental Bonding Instrument (PBI) - investiga o comportamento parental até os 16 anos do indivíduo.

Assim, ao realizar a coleta de dados por meio destes instrumentos foi possível a análise dos dados coletados a partir da identificação e categorização das variáveis relacionadas aos mesmos, de forma que: para as variáveis biológicas foram usados dados do ASI-6 e do questionário de perfil de consumo de crack; para as variáveis psicológicas foram usados o Mini Plus e alguns dados do questionário de perfil de consumo de crack; para as variáveis socioculturais foi usado apenas o ASI-6; em relação às variáveis de desenvolvimento utilizou-se o PBI, e já para a variável espiritual foi considerado algumas questões abordadas no ASI-6. Em seguida, foi possível a identificação dos estressores intrapessoais, interpessoais e extrapessoais, e a partir destes, foram identificados os diagnósticos de Enfermagem.

O diagnóstico de Enfermagem constitui: "julgamento sobre as respostas do indivíduo, família ou comunidade aos problemas de saúde e processos vitais." E acrescenta ainda que o diagnóstico proporciona base para a seleção de intervenções de Enfermagem na busca por resultados pelos quais o enfermeiro é responsável (16).

É importante destacar que as informações coletadas foram organizadas numa planilha Excel a fim de auxiliar na caracterização do estudo de caso. A partir daí, para se chegar aos diagnósticos foi utilizada a taxonomia II da North American Nursing Diagnosis Association - NANDA (16). 


\section{RESULTADOS}

O contato com E. L. R., 26 anos, foi realizado em sua primeira atividade no CAPSad - o grupo de acolhimento. Abaixo está descrita, de forma resumida, a história de vida do participante, relatada pelo mesmo durante este processo de coleta a partir dos instrumentos e que possibilitou a identificação das variáveis conforme o Modelo de Betty Neuman.

- Variáveis biológicas: E.L.R refere que teve o primeiro contato com o álcool nos primeiros meses de vida, sendo que nos últimos quinze anos usa mais de cinco drinques por dia. Nos últimos 12 meses, constatou que precisava de quantidades cada vez maiores e que quando bebia menos, as suas mãos tremiam, transpirava e sentia-se agitado. Estes, entre outros fatores caracterizam a dependência de álcool atual. Já sobre o consumo de crack, afirma que iniciou o consumo aos 19 anos motivado pela curiosidade. A partir daí, em cerca de trinta dias, o uso de crack se tornou frequente e mais intenso, consumindo naquela data, cerca de cinquenta pedras por semana e fazendo uso da droga quase todos os dias, sempre sozinho, no fim da noite/madrugada, por meio de latas encontradas na rua. Já teve sintomas como diminuição de energia, tremores, perda de peso, tosse, problemas de sono/insônia e convulsões, entre outros. Estas, entre outras questões, caracterizam a dependência de crack.

- Variáveis psicológicas: foram encontradas várias características relacionadas à comorbidades psiquiátricas, e a seguir foram destacadas cinco com suas características principais: 1 . nas últimas semanas sentiu-se triste, desanimado, deprimido, durante a maior parte do dia, quase todos os dias e em quase todo tempo teve o sentimento de não ter mais gosto por nada, de ter perdido o interesse e o prazer pelas coisas que lhe agradam, sentiu-se sem valor e culpado, quase todos os dias (aqui, afirma que "ah tenho vergonha do crack né... me sinto muito culpado por isso...”). - características estas de Episódio Depressivo atual; 2. mesmo sem estar sob o efeito do crack relata que teve um período em que se sentia tão eufórico e cheio de energia que isso lhe causou problemas, estava tão ativo e agitado que as outras pessoas se preocupavam por sua causa, os pensamentos corriam tão rapidamente na sua cabeça que não conseguia acompanhá-los, desejava tanto fazer coisas que lhe pareciam agradáveis ou tentadoras que não pensava nos riscos ou nos problemas que isso poderia causar (gastar demais). Afirma que estes problemas já duraram pelo menos uma semana e causaram dificuldades em casa, no trabalho e nas suas relações sociais -características estas relacionadas ao Episódio Maníaco passado; 3. afirma que já teve episódios repetidos durante os quais se sentiu subitamente muito ansioso mesmo em situações em que a maioria das pessoas não se sentiria assim -características estas relacionadas ao Transtorno de Pânico vida inteira; 4 . em vários momentos sente-se particularmente ansioso ou desconfortável em lugares ou em situações das quais é difícil ou embaraçoso escapar (como exemplo, ele diz: "fico muito... muito ansioso às vezes quando estou sozinho.. quando preciso resolver algo... já cheguei a procurar minha ex-mulher [pessoa com quem ele se envolveu, mas não foi casado] pra me ajudar porque sozinho eu não í conseguir... tava muito nervoso"). Afirma que tem tanto medo dessas situações que na prática, evita-as, sente um intenso mal-estar quando as enfrenta ou procura estar acompanhado ao ter que enfrentá-las -características estas relacionadas à Agorafobia; 5. Durante o último mês, teve, com frequência, pensamentos/ideias e impulsos angustiantes que voltavam repetidamente à sua mente, mesmo não querendo (afirma que já sentiu por várias vezes e ainda sente uma necessidade incontrolável de ordenar coisas). Neste ponto da entrevista, ele diz que "quando vou à casa da minha mãe e vejo um armário or- 
ganizado ou não, eu não aguento! Desarrumo e arrumo tudo de novo! E um saco, mas não aguento e faço de novo, e de novo...”. Afirma que já tentou, mas não conseguiu resistir a algumas dessas ideias ou ignorá-las. Acha que essas ideias são produto de seus próprios pensamentos. Mas, menciona que isto não aconteceu no último mês -características estas relacionadas à obsessões, mas não ao Transtorno obsessivo-compulsivo atual.

- Variáveis socioculturais: frequentemente tem dificuldades em como aproveitar o tempo livre. Afirma que está procurando por trabalho e pretende tentar fazer um curso supletivo (já sabe o local e já tem informações sobre o curso). Fez um curso para ser pintor, onde adquiriu um certificado (ao falar sobre este tema, sentiu-se animado, e disse: "Certificado? Ah! Isso eu tenho sim! Eu sou pintor! Fiz um curso e sou pintor! Ah... e também sou auxiliar de jardinagem! Pode colocar aî!"). Está muito endividado e atrasado em diversos pagamentos, pois não tem renda suficiente para pagar suas necessidades básicas comida, roupas e outros (aqui ele acrescenta o uso de álcool e crack). Em outro momento da entrevista quando questionado sobre roubos, de forma muito tímida e envergonhada ele abaixou a cabeça, desviou o olhar e disse: "ah... a minha mãe... roubei ela algumas vezes...". Afirma ainda que não tem nenhum amigo íntimo/verdadeiro. Neste momento, a expressão facial se torna entristecida, mas diz em tom de brincadeira: "ah... mas hoje em dia, ninguém é amigo de ninguém mesmo né.... Menciona que já teve várias discussões com seus parentes (afirma que estes têm vários problemas com uso de álcool -inclusive sua mãe). Neste ponto, E. L. R. ri (como se estivesse auto-ironizando sua situação) e diz: "nossa.. minha mãe.. meu Deus! Bebe demais! Muito mesmo, nunca vi igual!”.

- Variáveis de desenvolvimento: sobre a relação com mãe -afirma que nunca teve um bom relacionamento; ela sempre abusou muito do álcool e o faz até hoje. Após aplicação do PBI: categoria 'cuidado': pontuação de zero -nenhuma expressão de afeto ou cuidado até seus 16 anos; e no item 'superproteção' a pontuação foi de 19,3 - situações e episódios esporádicos de superproteção-caracterizando o 'Controle sem afeto'. Já sobre a relação com o pai -afirma que era rígido e raramente demonstrava algum afeto ou cuidado. Morreu assassinado quando E.L.R. tinha 14 anos. Pontuação de apenas 5 em relação ao item 'cuidado' e de 27 no item 'superproteção': -caracterizando o 'Controle sem afeto'.

- Variáveis espirituais: durante toda a entrevista menciona sempre o nome de Deus dizendo que 'Ele' de tudo sabe. Nos últimos trinta dias foi esporadicamente em alguma atividade religiosa.

Assim, a partir destas variáveis encontradas após aplicação dos instrumentos, foram selecionados diversos estressores intrapessoais (como uso de crack; ansiedade; baixa autoestima; isolamento social; impulsividade), estressores interpessoais (como ociosidade; uso de drogas pelos pais; enfrentamento familiar comprometido) e estressores extrapessoais (como falta de uma rede social de apoio; situação de rua) que afetam o sistema de equilíbrio do entrevistado, e por meio destes foram identificados 14 diagnósticos de Enfermagem.

- Estressores intrapessoais: foram identificados 9 diagnósticos de Enfermagem por meio da NANDA, em relação aos estressores intrapessoais. Isso se justifica pela influencia do uso do crack na subjetividade do indivíduo, interferindo em suas prioridades, medos e angústias.

Nesta categoria, os diagnósticos encontrados foram: conhecimento deficiente sobre o controle de substância; ansiedade; baixa autoestima crônica; desesperança; padrão de sono perturbado; religiosidade prejudicada; conflito no desempenho do papel de pai; iso- 
lamento social; enfrentamento ineficaz.

- Estressores interpessoais: foram identificados três diagnósticos de Enfermagem a partir dos estressores interpessoais que afetam o sistema de equilíbrio de E.L.R. São eles: atividades de recreação deficientes; enfrentamento familiar comprometido e risco de violência direcionada a outros.

- Estressores extrapessoais: foram dois os diagnósticos de Enfermagem identificados a partir dos estressores extrapessoais que afetam o sistema de equilíbrio de E.L.R. São eles: enfrentamento comunitário ineficaz e manutenção do lar prejudicada.

\section{DISCUSSÃO E CONCLUSÃO}

-Estressores intrapessoais: segue abaixo a discussão dos diagnósticos de Enfermagem encontrados a partir dos estressores intrapessoais:

Os estressores como o uso de crack e a falta de conhecimento sobre o controle das substâncias contribuíram para o diagnóstico de conhecimento deficiente sobre o controle de substância. Foi observado a partir da coleta de dados, que o usuário, E.L.R., iniciou o consumo de álcool muito precocemente, aos cinco anos. A partir de então, por curiosidade, foi motivado a fazer uso de outras drogas. Procurou o atendimento no CAPSad devido ao uso de crack, o qual julga ocasionar problemas de saúde, sociais, psicológicos, familiares, entre outros. Após aplicação dos instrumentos foram assinalados critérios para o diagnóstico de dependência de álcool e crack -que são, para ele, questões 'extremamente' preocupantes.

Observa-se que $o$ uso de crack se torna um estressor primordial no caso de E.L.R. e devido às características da dependência (fenômeno crônico e complexo), este fator de estresse subsistirá sempre, a nível intrapesso- al, porque é uma luta diária da vontade de E.L.R. face ao impulso de uso de crack, de forma que agrava a situação de diversos estressores já existentes, ao mesmo tempo em que cria novas dificuldades e problemas ao usuário.

Nesse contexto, a falta de conhecimento sobre o controle das substâncias é um potencial estressor intrapessoal que afeta de forma direta a linha normal de defesa do indivíduo e que pode desencadear problemas como a fissura e a consequente manutenção do uso de drogas:

- Ansiedade: foi um diagnóstico de Enfermagem identificado a partir do estressor ansiedade. É fácil perceber isso pela fala do entrevistado, pois ele relata que se sentiu excessivamente preocupado, inquieto, ansioso com relação a vários problemas da vida cotidiana e teve essas preocupações quase todos os dias durante os últimos seis meses. Assim, todas estas características apontam para o diagnóstico em questão de modo que a ansiedade se torna um estressor importante para o usuário e contribui para a dependência química.

Além disso, na coleta de dados, as respostas de E.L.R. foram condizentes com o diagnóstico de Transtorno de Pânico, e características como "se sentiu subitamente muito ansioso", "esses episódios atingiram intensidade máxima em 10 minutos e ocorreram sem motivo", "o coração bateu muito rápido, teve formigamentos pelo corpo, teve ondas de frio e calor", entre outras, contribuem também para esse diagnóstico de Enfermagem. Nesse sentido, Transtorno de Pânico é marcado por impetuosas crises de ansiedade e medo (17).

$\grave{E}$ interessante observar que alguns efeitos de ansiedade podem ser produzidos pelo próprio uso de drogas estimulantes. Assim, drogas estimulantes (como o crack) são capazes de produzir sintomas importantes de ansiedade, como dor no peito, taquicardia, sudorese, sensação iminente de morte - sin- 
tomas que também estão presentes em transtornos de ansiedade. Além disso, alguns sintomas da abstinência também podem produzir ansiedade, como tremores e sudorese (18). Logo, pacientes que já possuem esses quadros podem ter a sintomatologia e a frequência da ansiedade aumentada devido ao uso de crack.

Já em relação ao estressor baixa autoestima, foi identificado o diagnóstico baixa autoestima crônica. Esse aspecto está claro a partir da aplicação do instrumento MINI-Plus quando as perguntas são direcionadas a fim de procurar identificar um possível Episódio Depressivo. Isso se deve a várias respostas consideradas positivas, como "sentiu-se sem valor e culpado, quase todos os dias", sendo que foram situações muito associadas pelo paciente ao uso do crack que para ele seria motivo de vergonha e culpa.

Fato é que sentimentos de baixa autoestima são potenciais estressores intrapessoais para o uso de drogas, uma vez que favorece a desvalia, o sentimento de culpa e o desamparo, que interferem diretamente na tentativa de recuperação.

Assim, um estressor que esteve amplamente associado a este foi a desesperança que se trata de "estado subjetivo no qual um indivíduo não enxerga alternativas ou escolhas pessoais disponíveis ou enxerga alternativas limitadas e é incapaz de disponibilizar energia a seu favor" (16).

A desesperança então, neste caso, é percebida pela pesquisadora quando E.L.R. relata sentimentos de tristeza, desânimo, depressão, durante a maior parte do dia; de não ter mais gosto por nada, de ter perdido o interesse pelas coisas; ter passado a maior parte do tempo cansado, sem energia, entre os outros, que caracterizaram o Episódio Depressivo. E considerada, então, fator de estresse intrapessoal que contribui para que o usuário se sinta impotente diante das situações do cotidiano e diante do tratamento para o uso de drogas.

Do mesmo modo, o padrão de sono per- turbado foi um estressor intrapessoal importante identificado e possibilitou o diagnóstico de mesmo nome. Este diagnóstico foi percebido no processo de Depressão descrito pelo usuário, pois ele relata que por vezes teve problemas de sono, mas em noites esporádicas e que isso não teria relação com o uso de crack ou álcool.

Em uma pesquisa por meio de relatos de pessoas que estavam sendo atendidas no Consultório de Rua se observou que muitos apresentam um sono vigilante, pois qualquer distração pode resultar em agressões da parte de outros usuários -devido à fissura- que roubam ou agridem gratuitamente, assim dormir 'é um perigo' (19).

Fato é que esse estressor pode contribuir para o aumento da ansiedade e da procura pela droga, e no caso de E.L.R. deve ser considerado tanto a questão de uma possível depressão -e dessa forma a piora do sono-, como também a situação de rua que favorece o sono sempre vigilante.

- Religiosidade prejudicada: é importante considerar também que a variável espiritual é de suma importância em qualquer análise e deve ser abordada na intervenção do enfermeiro (12). No caso do paciente desta pesquisa, há uma grande preocupação sobre os desígnios de Deus, pois isto foi ressaltado por ele em vários momentos da entrevista.

No entanto, E.L.R. afirma que nos últimos trinta dias foi muito esporadicamente em alguma atividade religiosa e nem ao menos soube informar a última vez em que frequentou tal lugar. Assim, para o entrevistado a religiosidade prejudicada é um estressor intrapessoal importante que pode influenciar de forma significativa sua permanência ou não no tratamento.

E ainda, outro estressor intrapessoal identificado foi a possível paternidade que caracterizou o diagnóstico de conflito no desempenho do papel de pai. Fato é que E.L.R. quando perguntado sobre ter ou não filhos, mostrou dúvida na resposta. Para ele, há um 
conflito em desempenhar ou não este papel. Não sabe afirmar com certeza se a filha da mulher com quem se envolveu diz ser sua o é, ou não. Ao mesmo tempo, não demonstra preocupação em obter a resposta, apenas ri da situação. Mas, ainda assim, diz que tem uma filha de 7 anos, ou seja, teria sido gerada enquanto E.L.R. tinha apenas 19 anos -fase final de sua adolescência e ano em que iniciou o consumo de crack.

Fato é que ser pai e estar na fase de transição da adolescência para a idade adulta, muitas vezes, não é uma situação que se deseja vivenciar, até porque pode haver ainda imaturidade psicológica para lidar com tal questão. Assim, se deve considerar que E.L.R. possivelmente experimentou estressores nessa etapa, inclusive o início do uso de crack.

Outro estressor de grande importância foi o isolamento social. A partir das respostas de E.L.R. que possibilitaram a identificação de comorbidades como Transtorno do Pânico, Agorafobia, Fobia Social e Transtorno de Personalidade Anti-social foi conclusivo o diagnóstico de isolamento social, pois se aproxima de várias implicações desses problemas psiquiátricos. Além disso, este também pode ser no caso de E.L.R., decorrente do Episódio Depressivo apresentado pelo usuário.

E ainda a estas comorbidades, soma-se o fato de que E.L.R. procura se isolar também ao usar o crack, bem como se isolou do convívio com outras pessoas devido ao uso da droga, tornou-se mais desconfiado com outras pessoas e perdeu o interesse pelas outras pessoas.

Nesse sentido, diante dessas possíveis comorbidades é importante entender -de forma sucinta- as características das mesmas, pois pesquisas apontam alta prevalência de transtornos psiquiátricos em dependentes químicos, destacando-se o Transtorno de Personalidade (20). Neste sentido, foi realizado um estudo, a partir da aplicação do MINI- Plus, que observou nos dependentes de álcool/cocaína/crack maior presença de Transtornos de Personalidade - sugerindo a necessidade de tratamento diferencial para esta população (20).

É necessário lembrar ainda que usuários de substâncias psicoativas no início do tratamento podem apresentar variada sintomatologia física e psíquica que dificultam a adesão a qualquer abordagem e aumentam as chances de produzir contratransferência negativa, ampliando a possibilidade de diagnóstico errôneo de Transtorno de Personalidade (18). Mas, ainda é preciso salientar que entre as característica principais apontadas pelo MINI-Plus para este transtorno, como o medo persistente e excessivo de ser julgado e avaliado em situações sociais ou de desempenho foram apresentadas por E.L.R.

Já sobre o Transtorno de Pânico, os portadores são passíveis de adquirir Agorafobia - medo de permanecerem sozinhos em lugares públicos e assim, a pessoa tende a evitar situações sociais das quais não seja fácil escapar ou requerer socorro por temer ataque de pânico. Assim, cerca de $90 \%$ dos pacientes com Agorafobia apresentam crises de pânico (17) -dados que parecem se relacionar com a situação de E.L.R.

Em relação ao Episódio Depresssivo apresentado por E.L.R., observa-se relação tanto com o uso de crack quanto com a situação de rua. Em pesquisa (21) realizada com 245 homens adultos em situação de rua de Belo Horizonte encontrou-se alta prevalência dos quadros depressivos em decorrência de vulnerabilidades sociais vivenciadas, o que ressalta a importância de construção de políticas de saúde voltadas para esta população.

Situações todas que foram potenciais para contribuir para o estressor isolamento social, que neste caso pode estar atuando tanto como causa e/ou consequência dos episódios mencionados. É difícil nas primeiras consultas delinear essas questões, até porque o uso do crack e do álcool atual podem dificultar a diferenciação de tais diagnósticos de comorbidades. Assim, é importante que o enfermeiro encaminhe o paciente à especialidade médica de psiquiatria -se ainda não 
o foi realizado- e acompanhe suas condutas.

A identificação do isolamento social de E.L.R. é primordial em sua recuperação até porque o estressor atua de tal forma na vida de E.L.R. que contribui para a situação de rua-claro que isto também é influenciado pelo estressor maior o uso de crack-, pois em suas falas é possível perceber que ao procurar isolar-se de sua família e do contexto social com a finalidade de uso do crack -que passou a ser prioridade- encontrou como única solução a moradia na rua.

A situação de rua está relacionada à condição de extrema miséria e de vulnerabilidade a diversos fatores de risco para saúde, em geral com precários vínculos familiares e de trabalho, além da falta de acesso a bens materiais e sociais. Nesta situação, o indivíduo tem negado os direitos fundamentais - é de fato a "linha final do processo crônico de exclusão social” (21).

Fato é que o enfermeiro, na assistência ao usuário de crack, não deve se preocupar apenas com o uso de drogas e a abstinência, mas deve percebê-lo como um indivíduo que tem uma história, uma trajetória, desejos, crenças, valores e expectativas, o reconhecendo como um indivíduo que necessita de cuidado integral (22).

- Enfrentamento ineficaz: o diagnóstico de Enfermagem enfrentamento ineficaz se trata da "incapacidade de desenvolver uma avaliação válida dos estressores, escolha inadequada das respostas praticadas e/ou incapacidade de utilizar os recursos disponíveis" (16).

Estas questões são todas vivenciadas por E.L.R. diante do conjunto de estressores que afetam seu sistema de equilíbrio. Até porque por serem diversas situações que desencadeiam o desequilíbrio do seu sistema é fato que há um enfrentamento ineficaz dos estressores intra, inter e extrapessoal.

E, além disso, o uso do crack como estressor maior e possível desencadeante dos demais atua ainda no aumento da impulsividade de E.L.R. devido à ação da droga -es- timulante do SNC- e da intensa fissura. Fato é que a impulsividade, enquanto estressor intrapessoal favorece um enfrentamento ineficaz por parte do usuário.

Outra questão que deve ser considerada também nesse diagnóstico são os sintomas relatados por E.L.R. que indicam o diagnóstico de comorbidade de Episódio Maníaco Passado. O paciente afirma que mesmo sem estar sob o efeito do crack que se "sentia tão eufórico e cheio de energia que isso lhe causou problemas"; "tinha a sensação que podia fazer coisas que os outros seriam incapazes de fazer"; "os pensamentos corriam tão rapidamente na sua cabeça que não conseguia acompanhá-los"; "desejava tanto fazer coisas que lhe pareciam agradáveis ou tentadoras que não pensava nos riscos ou nos problemas que isso poderia causar (gastar demais)", entre outros. Situações essas que favorecem a impulsividade.

Assim, o consumo de cocaína/crack é percebido como uma forma de manter ou potencializar os quadros de Mania, sendo que o principal problema dos pacientes com essa comorbidade é a adesão ao tratamento (18).

- Estressores interpessoais: considerando que os indivíduos estão em constante troca de energia dinâmica com o ambiente (13), cabe ao enfermeiro auxiliar o paciente a se reorganizar conforme seus próprios recursos, e assim ajudá-lo na relação interpessoal o apoiando a assumir a responsabilidade pela melhora de sua qualidade de vida (23). Além disso, é importante considerar que o paciente deve necessitar também de um suporte social e familiar. Logo, com base nestas questões, se deve pensar em estressores interpessoais. Segue abaixo, a discussão dos diagnósticos encontrados a partir dos estressores interpessoais:

- Atividades de recreação deficientes: este diagnóstico diz respeito ao interesse diminuído em atividades recreativas ou de lazer, e sobre este item o usuário afirma que 
frequentemente tem dificuldades em como aproveitar o tempo livre. É fato, então, que a ociosidade é um estressor importante para E.L.R. até porque quanto menos atividades prazerosas a pessoa tiver, maior será a probabilidade de ocorrência de sentimentos negativos, como solidão e depressão. Sintomas estes, já descritos por E.L.R.

É preciso, então, implementar estratégias complementares que permitam fortalecer e diversificar a rede social do usuário, mas para isso há uma necessidade de articulação não só dos enfermeiros, mas da sociedade, governo e profissionais envolvidos com a temática a fim de se construir o avanço da rede de atenção aos usuários de substancias psicoativas, que seja de qualidade e eficaz (24). $\mathrm{E}$ assim, expandir as possibilidades em detrimento do uso de substâncias.

Além disso, são necessárias intervenções que venham auxiliá-lo, como a prática de atividades ocupacionais, física, recreativa e espiritual, facilitadoras da reinserção social do dependente (25).

- Enfrentamento familiar comprometido: a figura paternal e maternal, ambas ambíguas, que ao mesmo tempo demonstravam pouco ou nenhum cuidado (a mãe) e afeto, mas que tinham atitude de elevada superpoteção (principalmente o pai) caracterizou o 'controle sem afeto', durante a infância de E.L.R. Isso pode ter ocasionado repercussões em seu crescimento saudável, constituindo uma crise do desenvolvimento importante, que o afetou em nível da formação da personalidade.

Assim, estes eventos devem ser considerados fatores de estresse interpessoal, caracterizando o diagnóstico de enfrentamento familiar comprometido, de forma que qualquer crise do desenvolvimento assume-se como estressor para um indivíduo, mesmo que esta não lhe seja percepcionada como tal (10).

No que se refere à dependência química, a ideia básica é de que as pessoas que usam drogas estão em um contexto no qual seus valores, crenças, emoções e comportamentos influenciam os comportamentos dos demais membros da família e são por ela influencia$\operatorname{dos}(26)$.

- Risco de violência direcionada a outros: o diagnóstico de Enfermagem de risco de violência direcionada a outros está amplamente relacionado ao anterior, de forma que o enfrentamento ineficaz associado à impulsividade (como colocado anteriormente) favorece este diagnóstico. E mesmo considerando, pelo relato de E.L.R., que este nunca praticou nenhum ato de violência direcionada a outros, é fato que diante do uso de crack se deve considerar esse risco (27).

- Estressores extrapessoais: segue abaixo a discussão dos dois diagnósticos de Enfermagem encontrados a partir dos estressores extrapessoais:

- Enfrentamento comunitário ineficaz: este diagnóstico de Enfermagem foi proposto a fim de se pensar em meios para auxiliar E.L.R. em sua atual situação como morador de rua, uma vez que como "viver na rua só é uma escolha quando houver outras opções de vida" (28).

Apesar de essas questões terem sido pouco abordadas junto ao paciente, no momento da coleta, se percebe pelos relatos de E.L.R. que a sua atual situação de morador de rua é influenciada por inúmeros fatores, entre eles a ineficácia do enfrentamento comunitário que se mostra um estressor extrapessoal.

- Manutenção do lar prejudicada: a atual incapacidade de E.L.R. em manter um lar é um fator de estresse importante. Seu estado de desemprego, contas e dívidas a pagar, situação econômica comprometida, uso de crack e álcool constantes e problemas familiares tornaram este diagnóstico uma realidade 
para o usuário, contribuindo para situação de morador de rua.

Entre usuários de longa data é comum tanto o comprometimento da capacidade de recolocação no mercado de trabalho devido a déficits cognitivos, de assertividade quanto pela perda de habilidades sociais (25).

Assim, após a discussão dos principais diagnósticos identificados, é importante destacar que o uso de crack, não só no caso de E.L.R., surge diante de vários estressores anteriormente vivenciados, ou seja, contribui para ativar suas linhas de resistência e ainda desencadeia variados complicadores que 'passam a existir' decorrentes do uso da droga, de forma que o consumo o torna mais susceptível e vulnerável às situações reconhecidamente estressoras como a situação de rua.

Logo, a linha flexível de defesa, no caso de E.L.R. já perdeu grande parte da capacidade de recomposição devido aos vários estressores vivenciados por ele, o que contribui para o atual estado de dependência química e às possíveis comorbidades psiquiátricas.

Assim, o papel amortecedor da linha flexível de defesa já não tem mais efeito e não há outra constatação senão a invasão da linha normal de defesa pelos estressores, causando instabilidades em todo o sistema e reduzindo a capacidade de E.L.R. em lidar com quaisquer estressores adicionais. Logo, as linhas de resistências tornaram-se ativas e são gastos os recursos de energia da estrutura básica, ou 'Core'.

Compreende-se então que diante dos estressores intra, inter e extrapessoais (que podem conter simultaneamente uma variável sociocultural, psicológica, biológica, de desenvolvimento e/ou espiritual) identificados durante a coleta de dados, é fato que ocorreu rompimento das linhas de defesa do paciente.

Neste contexto, foi possível detectar que, em sua maioria, os estressores e assim, os diagnósticos estiveram relacionados ao aspecto intrapessoal, independente de quais variáveis implicadas. Outro fator importante no caso de E.L.R. foi a sua atual condição de morador de rua, que implicou em uma quantidade maior de diagnósticos e estressores (tanto intra, inter e extrapessoais).

Dessa forma, o estudo possibilitou constatar a complexidade que reveste as situações relativas aos estressores e propiciou um olhar amplo ao contemplar os aspectos primordiais na temática e todas as variáveis do modelo de Neuman.

Assim, o conhecimento deficiente sobre o controle de substância-crack e álcool-foi um dos diagnósticos mais significativos ao impedir que E.L.R. tenha iniciativas mais eficazes para lidar com um problema ainda maior - o próprio uso de crack. Há ainda questões relacionadas às possíveis comorbidades psiquiátricas e os sintomas decorrentes são pontos de extrema importância que devem ser focados pelo enfermeiro no decorrer do atendimento, pois influenciaram diretamente a vivência, pelo paciente, da maioria dos estressores identificados.

Dessa forma, a partir da pesquisa, constata-se que o uso de crack implica em diagnósticos de Enfermagem que relacionam diversos aspectos intra, inter e extrapessoais, de forma que a atuação do enfermeiro deve visar a uma recuperação ampla, e não somente a cessação do uso de crack, pois sem contemplar questões como reinserção social, família, o próprio desenvolvimento, entre outras, o paciente tende a se manter no estilo de vida anterior, quando em uso da droga. E o fato é que há muitos outros fatores na história de vida do indivíduo que favorece e mantém o uso.

Nesse sentido, o Modelo de Neuman facilitou a identificação dos diagnósticos de Enfermagem da NANDA, contribuindo para um 'novo olhar' do enfermeiro diante do usuário de crack ao considerar não só o uso da droga, mas sim os estressores e todas as variáveis do sistema. 


\section{REFERÊNCIAS}

1. Carlini EA, Galduróz JC, Noto AR, Carlini CM, Oliveira LG, Nappo AS et al. II Levantamento Domiciliar sobre o Uso de Drogas Psicotrópicas no Brasil: estudo envolvendo as 108 maiores cidades do país, 2005. São Paulo: CEBRID/ UNIFESP; 2007.

2. United Nations Office for Drug Control and Crime Prevention (UNODCCP). Global illicit drug trends 2010 [Internet]. Vienna: UNODCCP; 2010 [citado 2012]. Disponible en: www.unodc.org

3. Confederação Nacional dos Municípios. Pesquisa sobre a situação do crack nos municípios brasileiros. Brasília: CNM; 2010.

4. Kessler FHP, Pechansky F. Uma visão psiquiátrica sobre o fenômeno do crack na atualidade. Rev. psiquiatr. Rio Gd. Sul. 2008; 30(2): 1-3.

5. Cetlin GS. O Tratamento ao Usuário Compulsivo de Crack: Fissuras no Cotidiano Profissional. In: Sapori LF, Medeiros R, editores. Crack: um desafio social. Belo Horizonte: Editora PUC Minas; 2010. 220 p.

6. Ribeiro LA, Sánchez ZM, Nappo SA. Estratégias desenvolvidas por usuários de crack para lidar com os riscos decorrentes do consumo de droga. J. Bras. Psiquiatr. 2010; 59(3): 210-18.

7. Ribeiro M, Dunn J, Sesso R, Dias AC, Laranjeira R. Causes of death among crack cocaine users. Rev Bras Psiquitr. 2006; 28(3): 196-202.

8. Albuquerque BS. "Idade Doida da Pedra": Configurações Históricas e Antropológicas do Crack na Contemporaneidade. In: Sapori LF, Medeiros R, editores. Crack: um desafio social. Belo Horizonte: Editora PUC Minas; 2010. 220 p.

9. Fantauzzi GS, Aarão BFC. O Advento do Crack no Contexto Político Brasileiro. In: Sapori LF, Medeiros R, editores.
Crack: um desafio social. Belo Horizonte: Editora PUC Minas; 2010. 220 p.

10. Parker ME. Nursing Theories and Nursing Practice. Philadelphia: F.A. Davis Company, 2001. 338-41 p.

11. Cross J. Betty Neuman. In: George JB. et al. Teorias de Enfermagem: os fundamentos para a prática professional. Porto Alegre: Artes Médicas; 1993.

12. Neuman B. The Neuman Systems Model. $3^{\text {a }}$ ed. USA: Library of Congress; 1995. $732 \mathrm{p}$.

13. George, JB. Teorias de Enfermagem: os fundamentos à prática profissional. Porto Alegre: Artes Médicas; 2000.

14. Duarte PCAV, Pechansky F. Projeto Ações Integradas, componente 3: avaliação, estudo de polimorfismos genéticos, gerenciamento de caso e seguimento de usuários de crack que se encontram em tratamento em 6 capitais brasileiras. Porto Alegre: Secretaria Nacional de Políticas sobre drogas. Universidade Federal do Rio Grande do Sul; 2010.

15. Brasil. Ministério da Saúde. Conselho Nacional de Saúde. Resolução $\mathrm{n}^{\circ}$ 196/1996. Dispõe sobre as diretrizes e normas regulamentadoras de pesquisa envolvendo seres humanos. Bioética. n. 4, supl 2, p. 5-25. 1996.

16. Johnson M. Ligações entre NANDA, NIC e NOC. $2^{\mathrm{a}}$ ed. Porto Alegre: Artmed; 2009.

17. Velasco PM. Depressão e Transtornos Mentais. $2^{\mathrm{a}}$ ed. Copacabana, Brasil: WAK; 2009. 248p.

18. Cordeiro DC, Diehl A. Comorbidades Psiquiátricas. In: Diehl A, Cordeiro DC, Laranjeira R, editores. Dependência química: prevenção, tratamento e políticas públicas. Porto Alegre: Artmed; 2011.

19. Nery Filho A, Messeder ML. Exclusão ou desvio? Sofrimento ou prazer? In: Nery Filho A, MacRae E, Tavares LA, Rego M, editores. Toxicomania: incidência clínicas e socioantropológicas. Salvador: Editora da Universidade Federal da Bahia EDUFBA/UFBA, Centro de Estudos e 
Terapia do Abuso de Drogas CETAD/ UFBA; 2009. p. 23-123.

20. Scheffer M, Pasa GG, Almeida RMM. Dependência de álcool, cocaína e crack e transtornos psiquiátricos. Psic.: Teor. e Pesq. 2010; 26(3): 533-41.

21. Botti NCL, Castro CG, Silva MF, Silva AK, Oliveira LC, Castro ACHOA et al. Prevalência de depressão entre homens adultos em situação de rua em Belo Horizonte. J Bras Psiquiatr. 2010; 59(1): 10-6.

22. Arruda Filho J, Santos AE, Oliveira FS. Enfermagem na dependência química além das técnicas de contenção física e mecânica adequada. In: Diehl A, Cordeiro DC, Laranjeira R, organizadores. Dependência Química: Prevenção, Tratamento e Políticas Públicas. Porto Alegre RS: Artmed; 2011.

23. Pillon SC, Jora NP, Santos MA. O papel da equipe multidisciplinar na dependência química. In: Diehl A, Cordeiro DC, Laranjeira $R$, organizadores. Dependência Química: Prevenção, Tratamento e Políticas Públicas. Porto Alegre RS: Artmed; 2011.
24. Wandekoken KD, Siqueira MM. Discursos políticos e a rede de atenção aos usuários de substâncias psicoativas. Saúde em Debate. 2011; 35(88): 105-12.

25. Diehl A, Cordeiro DC, Laranjeira R, organizadores. Dependência Química: prevenção, tratamento e políticas públicas. Parte X, cap. 70. Porto Alegre: Artmed; 2011.

26. Payá R, Figlie NB. Abordagem familiar em Dependência Química. In: Figlie NB, Bordin S, Laranjeira R, organizadores. Aconselhamento em Dependência Química. São Paulo: Roca; 2004.

27. Guimaraes CF, Santos DVV, Freitas RC, Araujo RB. Perfil do usuário de crack e fatores relacionados à criminalidade em unidade de internação para desintoxicação no Hospital Psiquiátrico São Pedro de Porto Alegre (RS). Rev. psiquiatr. Rio Gd. Sul. 2008; 30(2): 101-8.

28. Vannucchi AMC, Cordeiro DC, Diehl A. Minorias. En: Diehl A, Cordeiro DC, Laranjeira R, organizadores. Depêndencia química: prevenção, tratamento e políticas públicas. Porto Alegre: Artmed, 2011. 